\title{
miRNA-mRNA profile and regulatory network in stearic acid-treated $\beta$-cell dysfunction
}

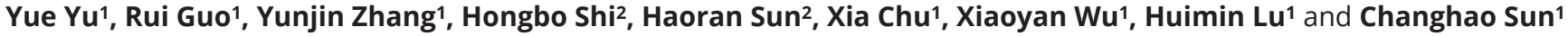 \\ 1Department of Nutrition and Food Hygiene (National Key Discipline), Public Health College, Harbin Medical University, Harbin, China \\ ${ }^{2}$ College of Bioinformatics Science and Technology, Harbin Medical University, Harbin, China
}

Correspondence should be addressed to H Lu or C Sun: Ihm_519@sina.com or changhaosun2002@163.com

\begin{abstract}
Chronic exposure of pancreatic $\beta$-cells to saturated fatty acid (palmitic or stearic acid) is a leading cause of impaired insulin secretion. However, the molecular mechanisms underlying stearic-acid-induced $\beta$-cell dysfunction remain poorly understood. Emerging evidence indicates that miRNAs are involved in various biological functions. The aim of this study was to explore the differential expression of miRNAs and mRNAs, specifically in stearic-acid-treated-relative to palmitic-acid-treated $\beta$-cells, and to establish their co-expression networks. $\beta$-TC- 6 cells were treated with stearic acid, palmitic acid or normal medium for $24 \mathrm{~h}$. Differentially expressed miRNAs and mRNAs were identified by high-throughput sequencing and bioinformatic analysis. Co-expression network, gene ontology (GO) and pathway analyses were then conducted. Changes in the expression of selected miRNAs and mRNAs were verified in $\beta-$ TC- 6 cells and mouse islets. Sequencing analysis detected 656 known and 1729 novel miRNAs. miRNA-mRNA network and Venndiagram analysis yielded two differentially expressed miRNAs and 63 mRNAs exclusively in the stearic-acid group. miR-374c-5p was up-regulated by a 1.801 log2(fold-change) and miR-297b-5p was down-regulated by a $-4.669 \log 2$ (fold-change). We found that miR297b-5p and miR-374c-5p were involved in stearic-acid-induced lipotoxicity to $\beta-T C-6$ cells. Moreover, the effects of miR-297b-5p and miR-374c-5p on the alterations of candidate mRNAs expressions were verified. This study indicates that expression changes of specific miRNAs and mRNAs may contribute to stearic-acid-induced $\beta$-cell dysfunction, which provides a preliminary basis for further functional and molecular mechanism studies of stearic-acid-induced $\beta$-cell dysfunction in the development of type 2 diabetes.
\end{abstract}

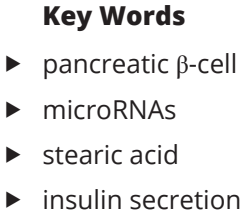

Journal of Endocrinology (2020) 246, 13-27

\section{Introduction}

The worldwide prevalence of type 2 diabetes mellitus (T2DM) has grown over the past three decades and continues to do so. It is characterized by insulin resistance and progressive failure of pancreatic $\beta$-cells (Smyth \& Heron 2006, Li et al. 2012, GBD et al. 2016, Chen et al. 2017). Chronic exposure to elevated saturated fatty acid (SFA) is a major risk factor for $\beta$-cell dysfunction that can accelerate the progression of T2DM (Welsh et al. 2005, Risérus et al.
2009, Giacca et al. 2011). SFA, including palmitic acid (C16:0) and stearic acid (C18:0), exerts deleterious effects on $\beta$-cells (Listenberger et al. 2003, Elsner et al. 2011). Palmitic acid has long been thought to be a major regulator of $\beta$-cell function; however, emerging evidence indicates that stearic acid also plays a critical role in $\beta$-cell dysfunction (Šrámek et al. 2017, Acosta-Montaño et al. 2019, Nemecz et al. 2019). We previously found that, compared with 
other non-esterified fatty acids (NEFAs), only stearic acid levels were dramatically increased in the postprandial serum of T2DM patients or in high-fat diet fed mice (Chu et al. 2013, Lu et al. 2016b). Meanwhile, high levels of stearic acid have a strong destructive effect on $\beta$-cells, stronger than that of palmitic acid (Lu et al. 2016a,b, 2018). Although generating endoplasmic reticulum (ER) stress (Lu et al. 2016a), alterations in calcium homeostasis (Marafie et al. 2019) and mitochondria dysfunction (Gehrmann et al 2010) have been reported to be involved in the stearic-acidinduced lipotoxicity to pancreatic $\beta$-cells, and its precise cellular and molecular mechanisms are complex and still need to be further elucidated.

miRNAs, a large family of small (21-25 nucleotides) noncoding RNAs found in plants, animals and some viruses, play a significant role in RNA silencing and regulation of gene expression at transcriptional and post-transcriptional levels (Ambros 2004, Bartel 2018). miRNAs regulate fundamental biological processes, such as cell proliferation, differentiation, angiogenesis and apoptosis (Flynt \& Lai 2008, Bartel 2018) and are also involved in multiple diseases (Jiang et al. 2009). Accumulated evidence indicates that miRNAs are often dysregulated in individuals suffering from T2DM (Flynt \& Lai 2008, Zhu \& Leung 2015, Pordzik et al. 2019). Zhu et al. observed that miR-26a regulates $\beta$-cell function and insulin signaling in $\mathrm{db} / \mathrm{db}$ T2DM mice (Song et al. 2018). Furthermore, miR-200 was identified to induce $\beta$-cell destruction and lethal T2DM (Belgardt et al. 2015). However, few studies have analyzed the expression profiles of miRNAs and mRNAs in stearic-acid-induced $\beta$-cell dysfunction, and comparison between stearic acid and palmitic acid treatment has not been reported.

In the present study, we employed Illumina HiSeq sequencing to create expression profiles for both miRNAs and mRNAs in untreated and stearic-acid- or palmiticacid-treated pancreatic $\beta$-TC- 6 cells. We selected miRNAs and mRNAs that were differentially expressed in the stearic-acid-treated group and built regulatory networks to reveal potential regulatory mechanisms controlling $\beta$-cell dysfunction induced by stearic acid. Our findings provide insight into the regulatory mechanism of noncoding RNAs in the development of T2DM.

\section{Materials and methods}

\section{Materials}

Stock solutions of stearic and palmitic acids (Sigma) supplemented with BSA ( $3 \mathrm{mmol} / \mathrm{L}$ fatty acid: $1.5 \mathrm{mmol} / \mathrm{L}$
BSA) were prepared as described previously (Goldstein et al. 1983). The working concentration for $\beta-T C-6$ cells was $400 \mu \mathrm{mol} / \mathrm{L}$. miR-297b-5p mimic, miR-374c-5p mimic, anti-miRNA-297b-5p oligonucleotides (AMO297b-5p), anti-miRNA-374c-5p oligonucleotides (AMO$374 c-5 p)$ and their negative controls were synthesized by Guangzhou RiboBio Co. Ltd. (Guangzhou, China).

\section{Cell culture}

$\beta$-TC-6 cells were obtained from Cell Library, Chinese Academy of Sciences (Shanghai, China) and incubated at $37.0^{\circ} \mathrm{C}$ in a $5 \%$ carbon dioxide incubator. Cells were cultured in Dulbecco's modified Eagle's medium (DMEM) supplemented with $1.5 \mathrm{~g} / \mathrm{L} \mathrm{NaHCO}_{3}, 15 \%$ fetal bovine serum (FBS) (Gibco) and $50 \mu \mathrm{g} / \mathrm{mL}$ streptomycin together with $50 \mathrm{IU} / \mathrm{mL}$ penicillin (Gibco). The $\beta$-TC- 6 cells were treated with $400 \mu \mathrm{mol} / \mathrm{L}$ stearic acid or palmitic acid for 24 h. Mouse islets were isolated after collagenase P (Cat. No. 11213873001, Roche Molecular Biochemicals) digestion of pancreas by ductal injection and purified with ficoll 400 (Cat. No. 17-0300-10, Pharmacia) as described previously (Sutton et al. 1986).

\section{Cell viability measurements}

Cell viability was determined by assessment of lactate dehydrogenase (LDH) release and Cell Counting Kit 8 (CCK 8) assays. For measuring LDH, culture medium was collected and analyzed using an LDH assay kit (Thermo Fisher Scientific). Cell Counting Kit 8 (C0038, Beyotime Biotechnology, Shanghai, China) was used to measure cell survival rate. Absorbance was determined using a SpectraMax M2 microplate reader (Molecular Devices, San Jose, CA, USA).

\section{Glucose stimulated insulin secretion (GSIS) assay}

$\beta$-TC-6 cells were incubated in secretion buffer ( $\mathrm{pH} 7.4)$ for $60 \mathrm{~min}$ with 2.8 or $20 \mathrm{mmol} / \mathrm{L}$ glucose, separately. Secretion buffer contained $\mathrm{NaCl} 129, \mathrm{KCl} 4.8, \mathrm{MgSO}_{4}$ 1.2, $\mathrm{KH}_{2} \mathrm{PO}_{4} 1.2, \mathrm{CaCl}_{2} 2.5, \mathrm{NaHCO}_{3}$ 5.0, and HEPES 10 $(\mathrm{mmol} / \mathrm{L})$ supplemented with $1 \mathrm{mg} / \mathrm{mL}$ BSA. The insulin level in cell culture medium was measured using a mouse/ rat insulin ELISA kit (Linco Research). After collecting the supernatant for insulin measurement, the $\beta$-TC- 6 cells were lysed in intermediate RIPA Lysis Buffer (Beyotime) for later evaluation of total protein content using a BCA protein assay reagent kit (Cat. No. P0010, Beyotime). https://joe.bioscientifica.com https://doi.org/10.1530/JOE-20-0055 (c) 2020 Society for Endocrinology Published by Bioscientifica Ltd. Printed in Great Britain 
The insulin levels were standardized by every milligram protein per hour in each well.

\section{RNA sequencing}

miRNA and mRNA sequencing using the Illumina HiSeq system (San Diego, CA, USA) was performed on three samples from each of the normal, stearic acid and palmitic acid groups by GENEWIZ (Suzhou, China). Total RNA from each sample was extracted using TRIzol reagent (Invitrogen) following the manufacturer's instructions and then quantified and qualified using an Agilent 2100 Bioanalyzer (Agilent Technologies), a NanoDrop spectrophotometer (Thermo Fisher Scientific) and 1\% agarose gel electrophoresis. For library preparation, $3^{\prime}$ and 5' SR Adaptors for Illumina were ligated to miRNAs using a specific ligation enzyme. Then, first strand cDNA was synthesized by ProtoScript II Reverse Transcriptase and amplified by PCR. Sequencing was performed using a $1 \times 50$ single-end (SE) $/ 2 \times 150$ paired-end (PE) configuration and further image analysis and base calling were conducted by the HiSeq Control Software (HCS) + OLB + GAPipeline-1.6 (Illumina) on the HiSeq instrument according to the manufacturer's instructions (Illumina).

\section{Quality control and differential expression analysis}

To achieve high quality clean data, pass filter data in FASTQ format were processed by Cutadapt (version 1.9.1) for miRNAs and Trimmomatic (v0.30) for mRNAs. All the identified miRNAs and their expression data were acquired according to miRDeep2. The DESeq/DESeq2 Bioconductor package, a model based on the negative binomial distribution, was used to perform differential expression analysis. After adjustment by Benjamini and Hochberg's approach for controlling the false discovery rate, $P<0.05$ was set to detect differentially expressed miRNAs and mRNAs.

\section{Functional enrichment analyses}

The underlying biological function of differentially expressed miRNAs and mRNAs was predicted by functional enrichment analysis including gene ontological and pathway analysis.

Gene ontology (GO) terms, which annotate a list of enriched genes with a significant $P$-value less than 0.05 , were identified by GO-TermFinder. We also used scripts in the Kyoto Encyclopedia of Genes and Genomes (KEGG) database (http://en.wikipedia.org/wiki/KEGG) to enrich significantly differentially expressed gene in KEGG pathways.

\section{Gene co-expression network construction}

Gene co-expression networks were constructed to reveal potential interactions among selected genes. The correlation for expression of selected miRNAs and mRNAs in cell samples was calculated by Pearson correlation coefficients (PCC). Only the miRNA-mRNA pairs with the strongest correlations ( $\mathrm{PCC} \geq 0.800$, or $\mathrm{PCC} \leq-0.800$, $P<0.05)$ were chosen to construct co-expression networks using Cytoscape software. Each gene corresponds to a node in the network.

\section{Animal experiments}

Seven-week-old male C57BL/6 mice were obtained from Vital River Laboratories Co. (Beijing, China) and randomly divided into normal diet (control, $n=10$ ) and high stearic acid diet (HSD, $n=10$ ) groups. The mice were housed in a temperature-controlled room and $60 \%$ relative humidity with non-restricted food and water. After 16 weeks, pancreatic tissue and blood samples were obtained for biochemical analysis. All animal procedures were approved by Institutional Animal Care and Use Committee of Harbin Medical University, and animals were maintained in line with the guidelines of the Animal Experimental Center of Harbin Medical University. A well-accepted approach using lard as a fat source to mimic high stearic acid diet was employed in this study, consistent with previous studies (van den Berg et al. 2010, Tholstrup et al. 2011, Lu et al. 2016a, Guo et al. 2020). Diet composition is displayed in Supplementary Table 1 (see section on supplementary materials given at the end of this article).

\section{Profile of serum NEFAs and lipid measurement}

Fasting serum NEFAs were transformed to fatty acid methyl esters as described previously (Chu et al. 2013). Gas chromatography-mass spectrometry analysis was performed using a TRACE gas chromatograph with a Polaris Q mass spectrometer (Thermo Finnigan, San Jose, CA, USA). Separation was obtained on a J\&W DB-WAX capillary column (30 m length, $0.25 \mathrm{~mm}$ inner diameter and $0.25 \mu \mathrm{m}$ film thickness; Agilent J\&W Scientific, Folsom, CA, USA). Heptadecanoic acid (C17:0) was used as an internal standard working solution. 
Table 1 Primer sequences used for qRT-PCR in this study.

\begin{tabular}{|c|c|}
\hline Gene & \\
\hline miR-297b-5p & $\begin{array}{l}\text { Reverse transcription } \\
\text { Forward } \\
\text { Reverse }\end{array}$ \\
\hline $\operatorname{miR}-374 c-5 p$ & $\begin{array}{l}\text { Reverse transcription } \\
\text { Forward } \\
\text { Reverse }\end{array}$ \\
\hline U6 & Reverse transcription \\
\hline & $\begin{array}{l}\text { Forward } \\
\text { Reverse }\end{array}$ \\
\hline ENSMUST0000007489 & $\begin{array}{l}\text { Forward } \\
\text { Reverse }\end{array}$ \\
\hline ENSMUST00000171621 & $\begin{array}{l}\text { Forward } \\
\text { Reverse }\end{array}$ \\
\hline ENSMUST00000086399 & $\begin{array}{l}\text { Forward } \\
\text { Reverse }\end{array}$ \\
\hline ENSMUST00000006956 & $\begin{array}{l}\text { Forward } \\
\text { Reverse }\end{array}$ \\
\hline ENSMUST00000050785 & $\begin{array}{l}\text { Forward } \\
\text { Reverse }\end{array}$ \\
\hline ENSMUST00000124100 & $\begin{array}{l}\text { Forward } \\
\text { Reverse }\end{array}$ \\
\hline ENSMUST00000092822 & $\begin{array}{l}\text { Forward } \\
\text { Reverse }\end{array}$ \\
\hline ENSMUST00000021620 & $\begin{array}{l}\text { Forward } \\
\text { Reverse }\end{array}$ \\
\hline ENSMUST00000073388 & $\begin{array}{l}\text { Forward } \\
\text { Reverse }\end{array}$ \\
\hline ENSMUST00000149884 & $\begin{array}{l}\text { Forward } \\
\text { Reverse }\end{array}$ \\
\hline$A c t b$ & $\begin{array}{l}\text { Forward } \\
\text { Reverse }\end{array}$ \\
\hline
\end{tabular}

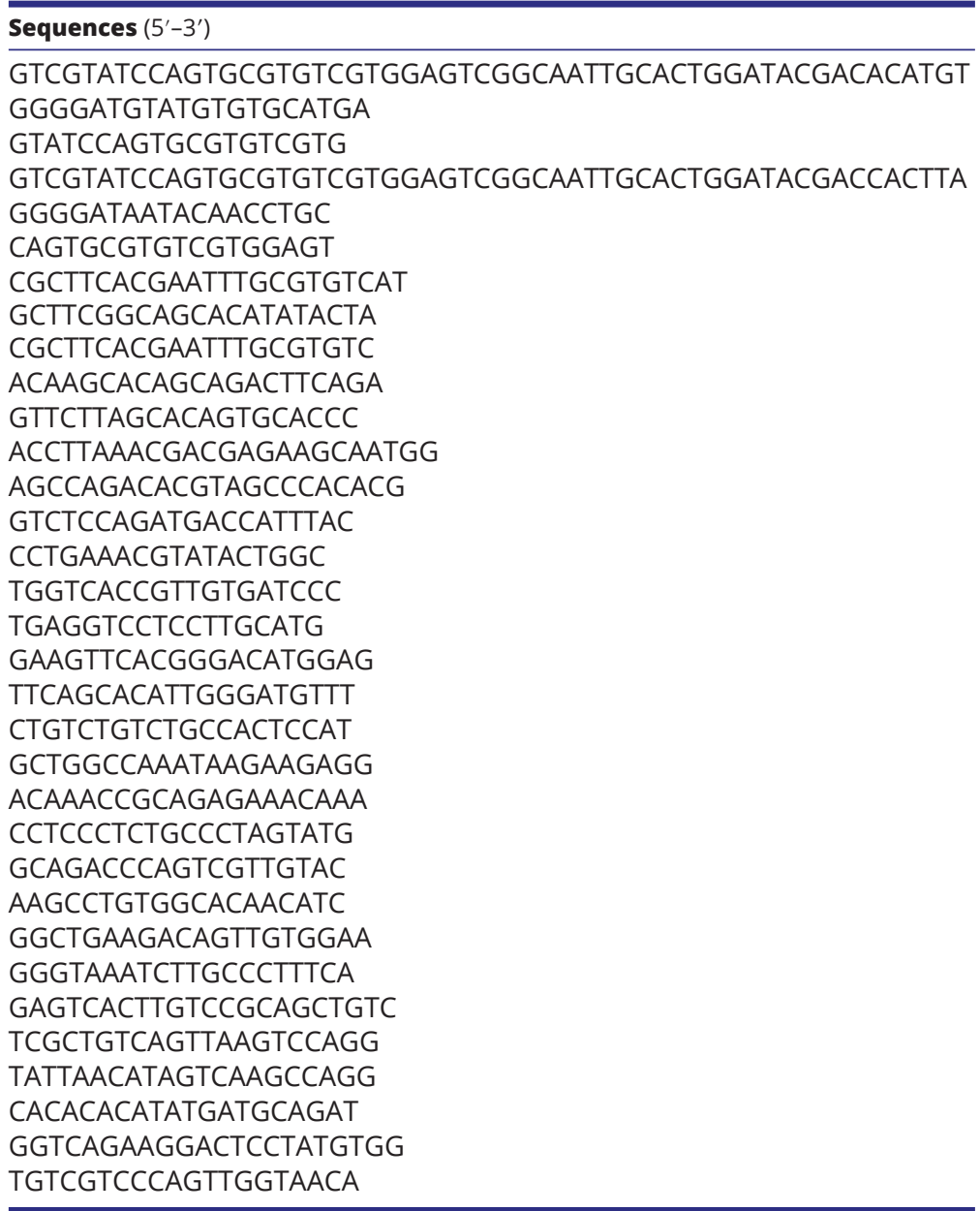

Serum total cholesterol (TC), triacylglycerol (TG), HDL, low density lipoprotein cholesterol (LDL-C) and glucose in the fasting state were calculated with an automatic analyzer (HITACHI-7100). All kits were purchased from Biosino Biotechnology Co. Ltd. (Beijing, China).

\section{Quantitative real-time PCR (qRT-PCR)}

To confirm high-throughput sequencing results, we performed quantitative real-time PCR (qRT-PCR) on cell and mouse samples. Total RNA with miRNAs was isolated using TRIzol reagent (Invitrogen) according to the manufacturer's instructions. Total RNA $(1 \mu \mathrm{g})$ was reverse transcribed to cDNA in a $20-\mu \mathrm{L}$ reaction system using a High Capacity cDNA Reverse Transcription Kit (Applied Biosystems). Realtime PCR was performed using Power SYBR ${ }^{\circledR}$ Green PCR Master Mix and a 7500 FAST Real-time PCR System (Applied Biosystems). U6 and Actb were used as internal controls for measurement of miRNA and mRNA levels, respectively. The primer sequences are shown in Table 1.

\section{Statistical analysis}

All data are presented as mean \pm S.E.M. In Supplementary Tables 7 and 8, values are expressed as the mean \pm s.D. Twotailed Student's $t$-test and one-way ANOVA were performed to compare two or three groups, respectively, using SPSS 21.0 (Beijing Stats Data Mining Co., Beijing, China). A value of $P<0.05$ was considered statistically significant.

\section{Results}

\section{Stearic acid stimulates stronger lipotoxicity than} palmitic acid in $\beta$-TC- 6 cells

CCK 8 and LDH assays showed that lipotoxicity was significantly enhanced in the stearic-acid-treated $\beta$-TC-6 cells compared with control and palmitic-acid-treated cells (Fig. 1A and B). Meanwhile, GSIS was lower in the stearic-acid-treated cells than in cells treated with palmitic acid (Fig. 1C). 


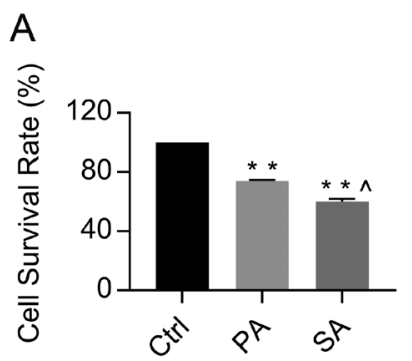

B

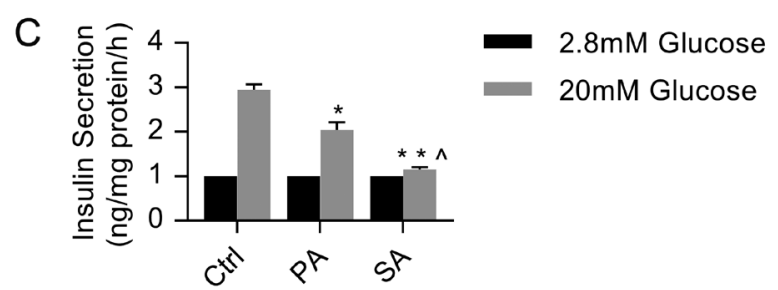

Figure 1

Stearic acid stimulates stronger lipotoxicity in $\beta$-TC- 6 cells than palmitic acid. (A and B) Effect of stearic acid and palmitic acid on cell viability determined by CCK 8 and LDH assays, respectively. (C) Comparison of impaired glucose-stimulated insulin secretion (GSIS) by stearic acid and palmitic acid. ${ }^{\star} P<0.05,{ }^{*} P<0.01$, compared to the Ctrl group; ${ }^{\wedge} P<0.05$ vs PA group. Ctrl, control group; PA, palmitic acid; SA, stearic acid. All representative data are shown as the mean \pm S.E.M. and are from triplicate experiments.

\section{The miRNA profile and differentially expressed miRNAs in stearic-acid-treated relative to palmitic- acid-treated $\beta$-TC- 6 cells}

Sequencing analysis detected 656 known and 1729 novel miRNAs. Hierarchical clustering showed distinguishable miRNA expression profiles in the three groups (Fig. 2A). Differentially expressed miRNAs were screened based on $\log 2$ (fold-change) and $P$-value $\leq 0.05$. As shown in our previous study (Guo et al. 2020), after palmitic acid treatment, five transcripts were significantly up-regulated and one was down-regulated, compared with the control group. In the stearic acid group, the expression level was increased for 13 miRNAs and decreased for three. Based on the Venn diagram (Guo et al. 2020), two miRNAs were expressed exclusively in the stearic acid group; miR$374 \mathrm{c}-5 \mathrm{p}$ was up-regulated by $1.801 \log 2$ (fold-change) and miR-297b-5p was down-regulated by $-4.669 \log 2$ (foldchange) (Fig. 2B). In palmitic-acid-treated $\beta$-TC-6 cells, only NovelmiRNA-639 was differentially expressed with an increase of $5.107 \log 2$ (fold-change) (Supplementary Table 2), compared both with control and stearic acid group. Meanwhile, miR-21a-5p and miR-34a-5p were significantly up-regulated both in stearic and palmitic acid group (Supplementary Table 3), compared with normal group.

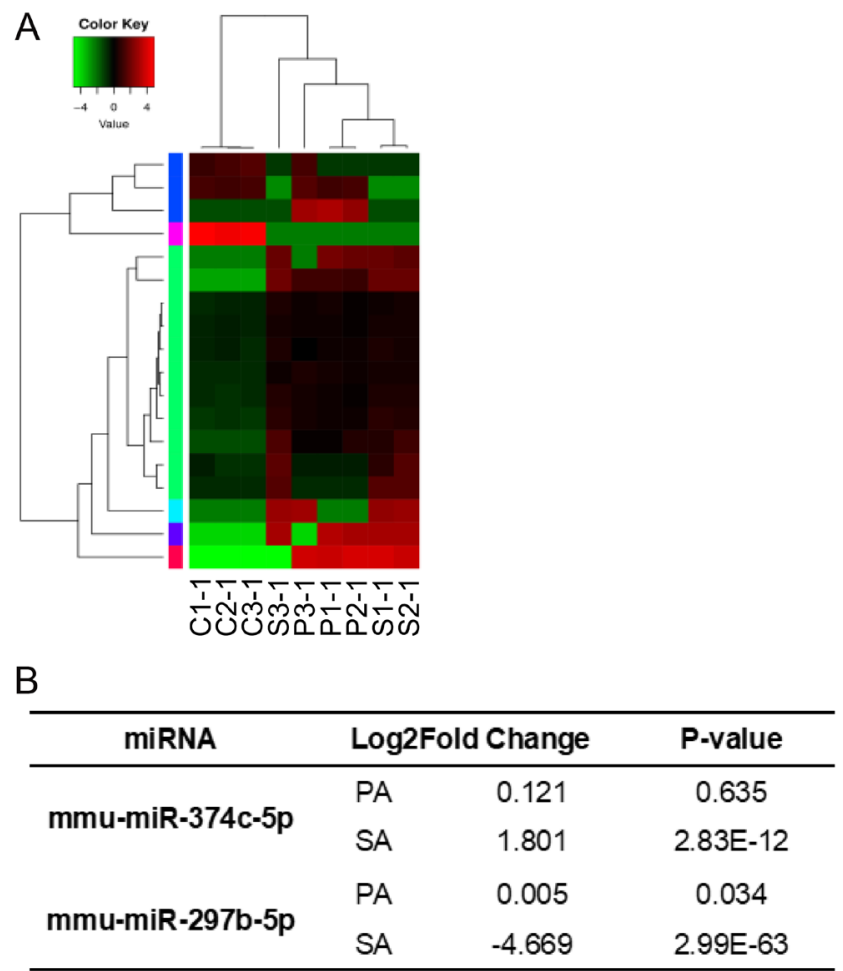

\section{Figure 2}

The profile and differential expression of miRNAs in stearic-acid-induced $\beta$-TC- 6 cells compared with palmitic-acid-treated and control groups. (A) Hierarchical clustering of differentially expressed miRNA genes in nine samples with $\log 2$ (TPM) values. The dendrogram shows the relationship between expression in the control group and in cells exposed for $24 \mathrm{~h}$ to stearic acid or palmitic acid. Red denotes high expression levels, whereas green depicts low expression levels. From green to red, the miRNA expression increases. C, control group; $S$, stearic acid group; $P$, palmitic acid group. (B) RNA sequencing data displays the log2(fold-change) of candidate miRNAs in stearic-acid- and palmitic-acid-treated $\beta$-TC-6 cells. $\mathrm{PA}$, palmitic acid; SA, stearic acid. A full color version of this figure is available at https://doi.org/10.1530/JOE-20-0055.

\section{The mRNA profile and differentially expressed mRNAs in stearic-acid-treated relative to palmitic- acid-treated $\beta$-TC- 6 cells}

To identify potential miRNAs targets, 103,640 mRNAs were detected in nine samples. Samples were clustered into three distinct groups. Hierarchical clustering of the expression profiles of mRNAs revealed that mRNA expression profiles can largely distinguish the stearic-acid and palmiticacid-induced lipotoxicity of $\beta$-TC-6 cells (Fig. 3A). An average of 658 mRNAs was significantly up-regulated in palmitic-acid-induced $\beta$-TC- 6 cells, compared with the control group, while an average of 247 mRNAs was downregulated (Fig. 3B). In the stearic acid group, 1333 mRNAs were up-regulated and 572 were down-regulated (Fig. 3B). Of these, 63 mRNAs were specifically expressed in stearicacid-treated $\beta$-TC- 6 cells compared with the control 
A

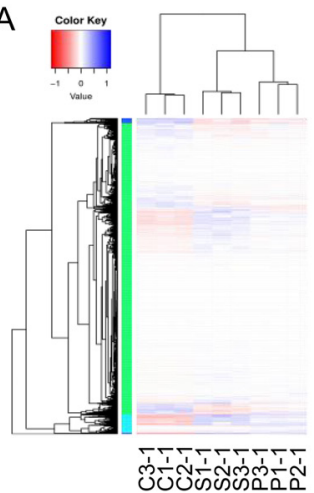

B

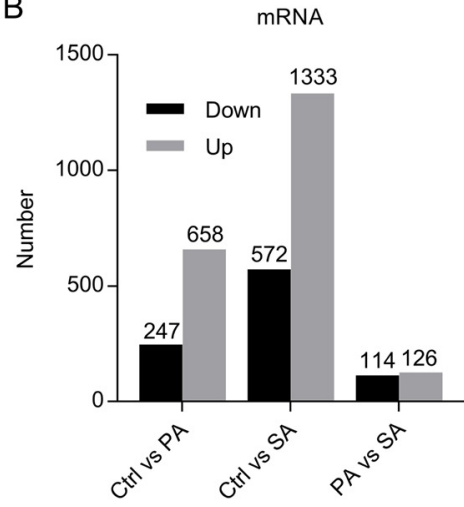

C

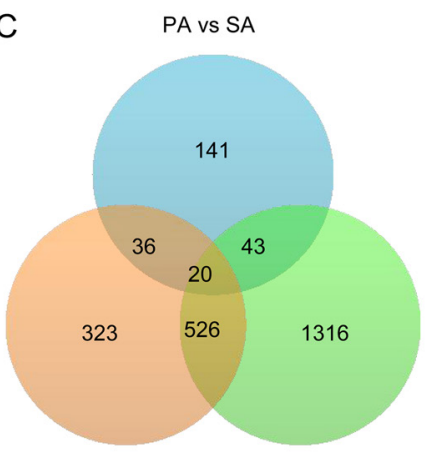

Ctrl vs PA

Ctrl vs SA

\section{Figure 3}

The profile and differential expression of mRNAs in stearic-acidstimulated $\beta$-TC- 6 cells compared with control and palmitic-acid-treated cells. (A) Heatmap showing the hierarchical cluster analysis of differential mRNA expression profiles with $\log _{10}(F P K M+1)$ values in stearic-acid- and palmitic-acid-treated $\beta$-TC- 6 cells vs control cells. The scale bar indicates the level of mRNA expression: blue, high level of expression; red, low level of expression. From red to blue, the mRNA expression increases. C, control group; $S$, stearic acid group; $P$, palmitic acid group. (B) Screening of differentially expressed mRNAs between two groups. Up- and down-regulated genes are colored red or blue, respectively. (C) The Venn diagram shows the number of differentially expressed mRNAs between two groups. Ctrl, control; PA, palmitic acid; SA, stearic acid. A full color version of this figure is available at https://doi.org/10.1530/JOE-20-0055.

group; 39 were up-regulated and 24 were down-regulated (Fig. 3C and Supplementary Table 4). While in palmitic acid group, 56 mRNAs were differentially and specifically expressed (Supplementary Table 5). In addition, 546 mRNAs were differentially expressed both in stearic acid and palmitic acid group, among which the top ten upand down-regulated differentially expressed mRNAs were shown in Supplementary Table 6.

\section{Gene ontology and pathway analysis}

To identify the potential roles of differentially expressed miRNAs and mRNAs in stearic-acid-induced $\beta$-cell dysfunction, we first performed GO analysis on the basis

of biological process, cellular component and molecular function in the GO database. After setting the cut-off as $\mathrm{FDR} \leq 0.05$, the most significant GO functions were related to molecular function, cellular component and biological process. Moreover, we further performed pathway enrichment analysis based on the pathway information in the KEGG database to clarify potential function. As shown in Figs 4 and 5, these miRNAs and mRNAs were mainly involved in GO terms, binding, cell part, cell process and biological regulation (Fig. 4A, B, C, D, E and F) and in KEGG pathways, long-term potentiation, insulin secretion, vascular smooth muscle contraction, and type 2 diabetes (Fig. 5A, B, C, D, E and F). The mRNAs were associated with apoptosis, inflammation, antioxidant activity and insulin exocytosis pathways, which are closely associated with islet $\beta$-cell function.

\section{Construction of a miRNA-mRNA co-expression network}

In an effort to reveal the relationship between miRNAs and target mRNAs specifically expressed in stearic-acid-treated $\beta$-cells, a miRNA-mRNA network was constructed as described in the Materials and methods. The network contained two miRNAs and 96 mRNA (48 positive correlated pairs and 48 negative correlated pairs, respectively) (Fig. 6A and B). The mRNA that is most positively associated with miR297b-5p is ENSMUST00000135138 (predicted gene 15350 (Gm15350)) (PCC=0.996). In contrast, the most negatively related mRNA to miR-297b-5p is ENSMUST00000022531 (large tumor suppressor 2 (Lats2)) (PCC $=-0.995)$. For miR374c-5p, ENSMUST00000135828 (zinc finger protein 783 $(Z f p 783)$ ) is the most positively correlated gene ( $\mathrm{PPC}=0.990)$ and ENSMUST00000185596 (SLIT-ROBO Rho GTPase activating protein 2 (Srgap2)) is the most reversely related gene (PCC $=-0.901$ ). Additionally, as for miRNAs and target mRNAs exclusively expressed in palmitic acid group, one miRNA and 41 mRNAs (33 positive correlations and eight negative correlations, respectively) were included in the co-expression network (Fig. 6C and D), among which ENSMUST00000031327 (chemokine (C-X-C motif) ligand $1(\mathrm{Cxcl1}))(\mathrm{PCC}=0.996)$ is the most positively correlated gene and ENSMUST00000170237 (unc-51-like kinase 4(Ulk4)) $(\mathrm{PCC}=-0.977)$ is the most negatively related gene.

\section{Animal model characteristics}

A high-stearic-acid diet fed in vivo mouse model mimicking increased proportions of stearic acid was successfully established, as evidenced by significant elevation of 

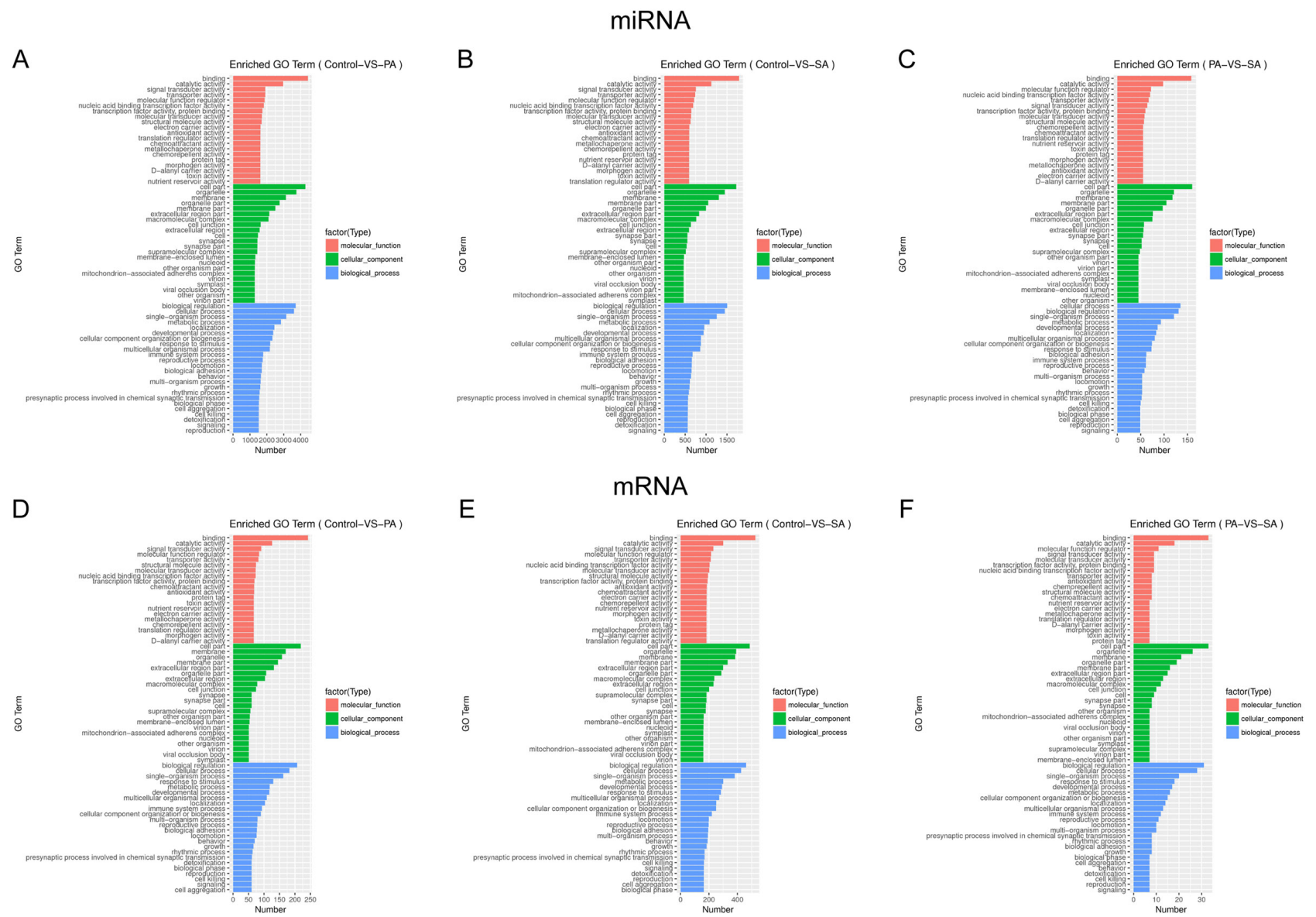

\section{Figure 4}

Functional enrichment map of GO terms. The GO terms of predicted target genes of differentially expressed miRNAs (A, B and C) and mRNAs (D, E and F). The vertical coordinate is the enriched GO term, and the horizontal coordinate is the number of different miRNA target genes in the term. Different colors are used to distinguish biological processes, cell components and molecular functions. PA, palmitic acid; SA, stearic acid. A full color version of this figure is available at https://doi.org/10.1530/JOE-20-0055.

circulating stearic acid (Supplementary Table 7). The metabolic characteristics of these animals are summarized in (Supplementary Table 8).

\section{Verification of expression for candidate miRNAs and mRNAs}

To confirm differential expression of miRNAs and mRNAs by Illumina HiSeq sequencing analysis, quantitative real-time PCR was performed on $\beta$-TC- 6 cells incubated with stearic acid and on islets from high-stearic-acid-fed mice. The two miRNAs (miR-374c-5p and miR-297b-5p) and the five most up-regulated (ENSMUST00000074898, ENSMUST00000171621, ENSMUST00000086399, ENSMUST00000006956 and ENSMUST00000050785) and down-regulated (ENSMUST00000124100, ENSMUST00000092822, ENSMUST00000021620, ENSMUST00000073388 and ENSMUST00000149884) mRNAs were chosen for further verification (Table 2). In stearicacid-treated $\beta$-TC- 6 cells, miR-374c-5p was significantly increased by 3.98 -fold, while miR-297b-5p was decreased by $41.12 \%$, compared with the normal group (Fig. 7A). In mouse islets, the expression of miR-374c-5p was also obviously up-regulated in the high-stearic-acid-fed group, while miR-297b-5p was down-regulated compared with normal mice (Fig. 7B). For all mRNAs, expression in $\beta$-TC- 6 cells and mouse islets was consistent with the RNA-Seq results (Fig. 7C and D). Additionally, in AML-12 cells treated with stearic acid, the level of miR-374c-5p was consistent with the RNA sequencing results, but miR297b-5p showed the opposite results (Fig. 7E). Meanwhile, in various tissues, the expression of miR-297b-5p was increased in liver and brown fat but decreased in skeletal muscle, testicular fat and perirenal fat. The level of miR-374c-5p was up-regulated in liver and brown fat but down-regulated in testicular fat and perirenal fat. 


\begin{tabular}{l|l|l|l|l|}
$\begin{array}{l}\text { Journal of } \\
\text { Endocrinology }\end{array}$ & Y Yu et al. & $\begin{array}{l}\text { miRNA-mRNA profile in } \\
\text { SA-induced } \beta \text {-cell injury }\end{array}$ & $246: 1$ & 20 \\
\hline
\end{tabular}

A

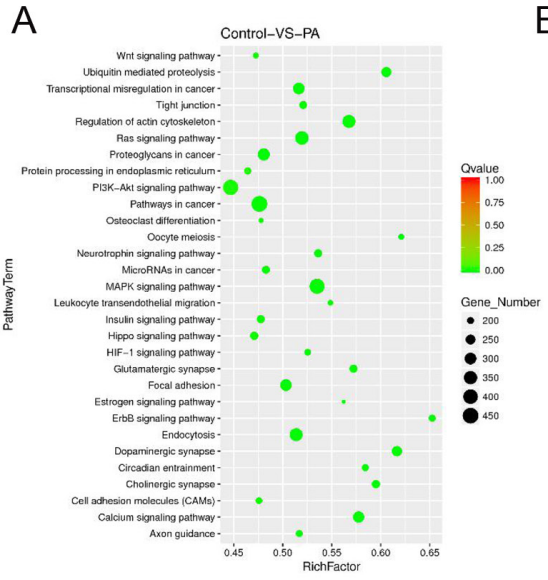

$\mathrm{D}$
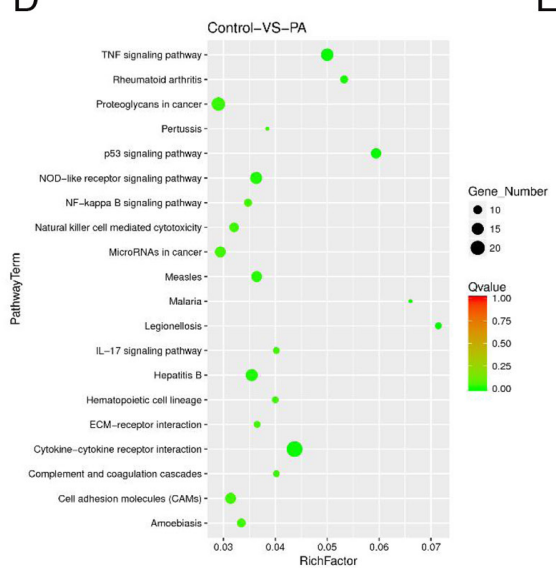

B

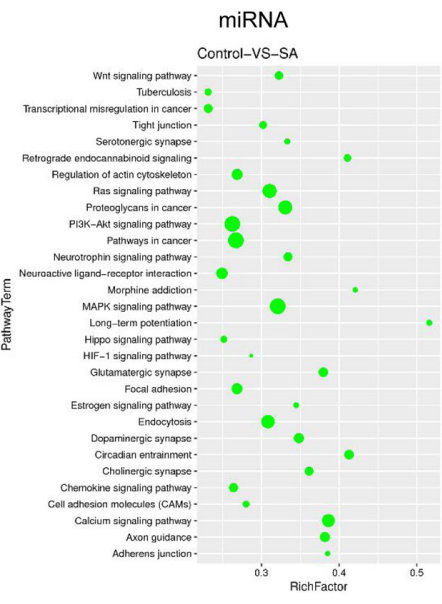

$E$

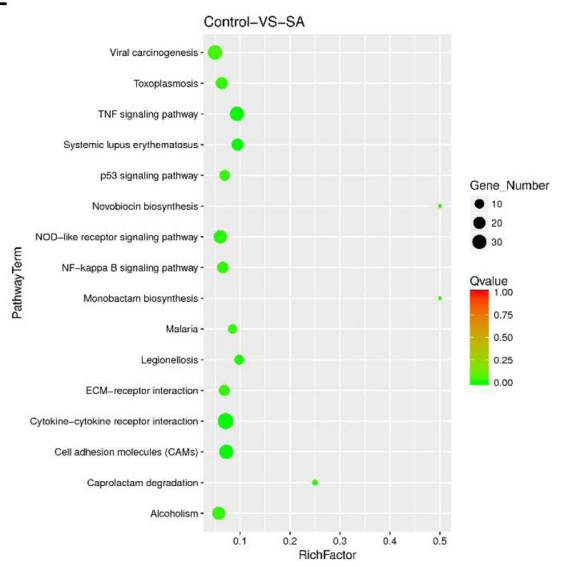

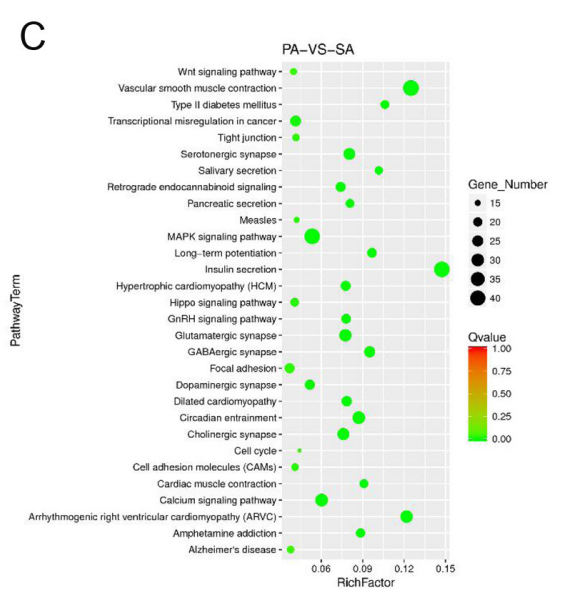

F

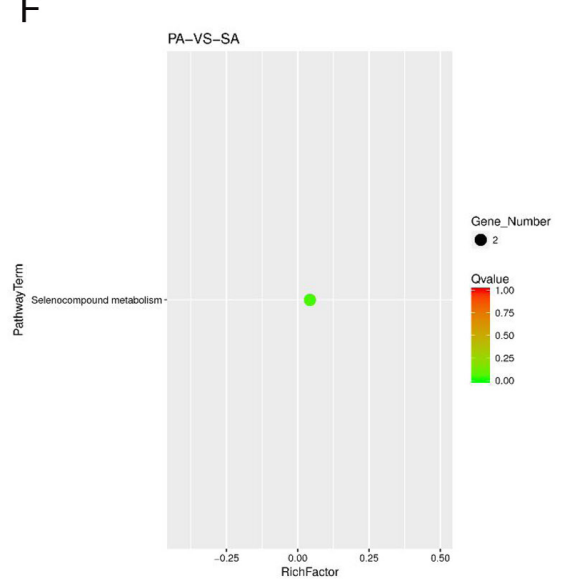

Figure 5

Significantly enriched KEGG pathways for miRNAs and mRNAs. KEGG pathways for predicted target genes of differentially expressed miRNAs (A, B and C) and mRNAs (D, E and F). The vertical axis represents the pathway name, the horizontal axis represents enrichment factor and the size of the point represents the number of differentially expressed miRNA target genes in the pathway, while the color of the point corresponds to the Q value range. PA, palmitic acid; SA, stearic acid. A full color version of this figure is available at https://doi.org/10.1530/JOE-20-0055.

For miR-374c-5p, no alteration was observed in skeletal muscle (Fig. 7F).

\section{Involvement of miR-297b-5p and miR-374c-5p in stearic-acid-induced lipotoxicity to $\beta$-TC- 6 cells}

We then tested whether the changes in the expression of miR-297b-5p and miR-374c-5p affect $\beta$-cell viability and function. The transfection efficiency was displayed in Fig. 8A. Transfection of miR-297b-5p mimic and AMO-297b-5p alone into $\beta$-TC-6 cells apparently up-regulated and inhibited intracellular miR-297b-5p levels, respectively. Meanwhile, overexpression of miR-297b-5p significantly reversed stearic-acid-decreased miR-297b-5p expression (Fig. 8B). Furthermore, miR-297b-5p up-regulation markedly alleviated stearic-acid-induced cell death (Fig. 8C) and impaired insulin secretion (Fig. 8D). Similar results were observed after transfection of miR-374c-5p mimic or AMO. The expression of miR-374c-5p was significantly increased and decreased by addition of its mimic and AMO, respectively (Fig. 8E). Inhibition of miR$374 c-5 p$ remarkably reversed stearic-acid-increased miR374c-5p expression (Fig. 8F). In addition, knockdown of miR-374c-5p significantly blocked stearic-acid-stimulated decrease of cell survival rate (Fig. 8G) and reduction of insulin secretion (Fig. 8H). However, incubation of $\beta$-TC-6 cells with miR-297b-5p mimic or AMO-374c-5p alone did not significantly alter the cell viability (Fig. 8C and D) and insulin secretion (Fig. 8G and H).

\section{Effect of miR-297b-5p and miR-374c-5p on the expressions of candidate mRNAs in stearic-acid- treated $\beta$-TC- 6 cells}

After transfection of miR-297b-5p mimic into $\beta$ TC-6 cells, the stearic-acid-increased expressions of 
A

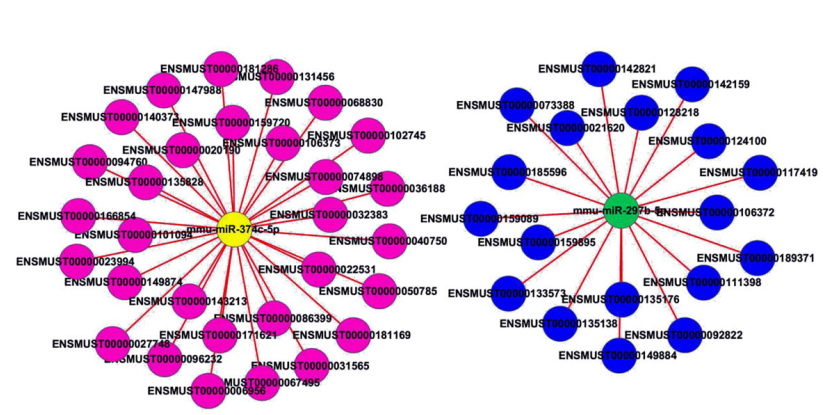

B

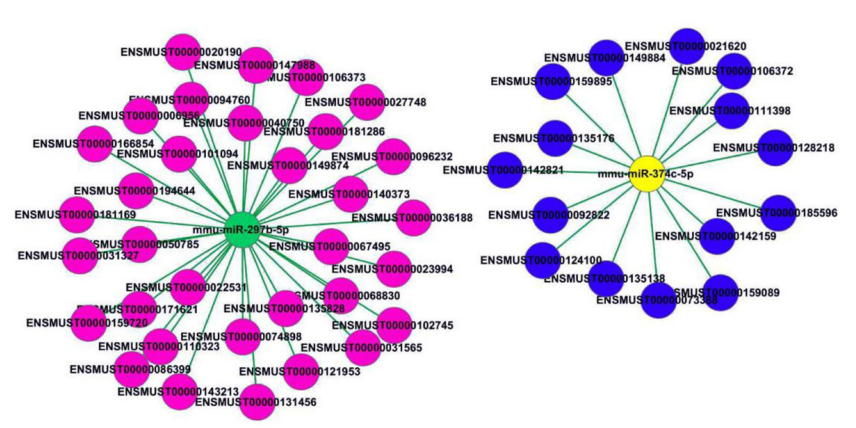

C

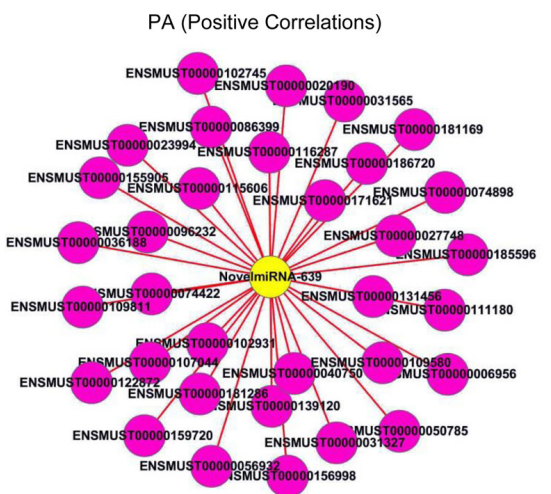

D

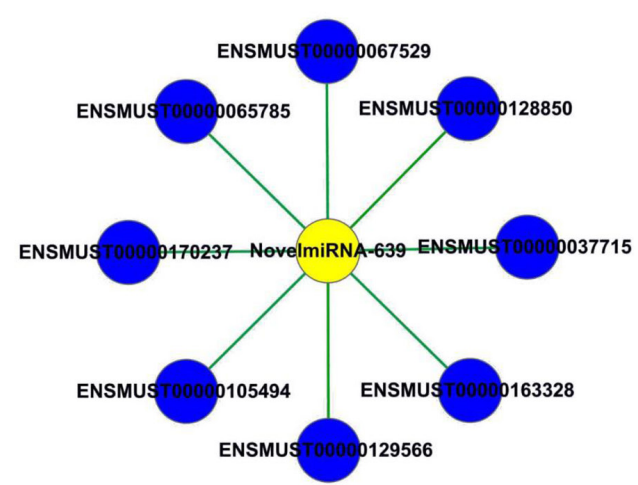

\section{Figure 6}

The co-expression network of differentially expressed miRNAs and mRNAs. (A) The candidate miRNAs are significantly correlated (positive) with corresponding mRNAs specifically in stearic-acid-treated $\beta$-TC- 6 cells, compared both with palmitic acid and control group. (B) The negative correlations between miRNAs and mRNAs exclusively differentially expressed in stearic acid group. (C) The co-expression network is composed of one miRNA and its positive related mRNAs specifically in palmitic-acid-treated $\beta-T C-6$ cells, compared both with palmitic acid and normal group. (D) The miRNA is significantly reversely correlated with mRNAs specifically differentially expressed in palmitic-acid-treated cells, compared both with stearic-acid-treated and untreated cells. Genes colored in yellow and pink represent up-regulated miRNAs or mRNAs, separately. Green and blue nodes represent downregulated miRNAs and mRNAs, respectively. Red lines refer to positive correlation and green lines represent negative correlation. A full color version of this figure is available at https://doi.org/10.1530/JOE-20-0055.

ENSMUST00000074898, ENSMUST00000171621 and ENSMUST00000006956 (Fig. 9A), as well as stearicacid-decreased ENSMUST00000092822 and ENSMUST00000149884 (Fig. 9B) were significantly reversed.
When transfected with miR-297b-5p mimic alone, the five most down-regulated mRNAs ENSMUST00000124100, ENSMUST00000092822, ENSMUST00000021620, ENSMUST00000073388 and ENSMUST00000149884

Table 2 Top five up- and down-regulated differentially expressed mRNAs specifically in stearic-acid-induced $\beta$-TC 6 cells compared both with palmitic acid and control group.

\begin{tabular}{l}
\hline Ensemble gene ID \\
\hline ENSMUST00000074898 \\
ENSMUST00000171621 \\
ENSMUST00000086399 \\
ENSMUST00000006956 \\
ENSMUST00000050785 \\
ENSMUST00000124100 \\
ENSMUST00000092822 \\
ENSMUST00000021620 \\
ENSMUST00000073388 \\
ENSMUST00000149884
\end{tabular}

\section{Gene name}

Haptoglobin $(H p)$

TRAF-interacting protein with forkhead-associated domain (Tifa) intercellular adhesion molecule 1 (Icam1)

serum amyloid A 3 (Saa3)

lipocalin 2 ( LCn2)

prion protein gene complex (Prn)

breast carcinoma amplified sequence 3 (Bcas3)

OTU domain, ubiquitin aldehyde binding 2 (Otub2)

Arylformamidase (Afmid)

SNAP-associated protein (Snapin)

\begin{tabular}{c}
\hline Log2 fold change \\
\hline 6.940 \\
6.641 \\
6.190 \\
6.127 \\
5.881 \\
-5.858 \\
-5.561 \\
-5.161 \\
-4.336 \\
-4.299
\end{tabular}

PValue $7.854 \mathrm{E}-126$

$2.468 \mathrm{E}-67$

$3.981 \mathrm{E}-73$

$5.323 \mathrm{E}-112$

4.656E-53

$5.451 \mathrm{E}-53$

1.597E-40

$1.512 \mathrm{E}-36$

$1.323 \mathrm{E}-24$

$1.348 \mathrm{E}-24$ 
A

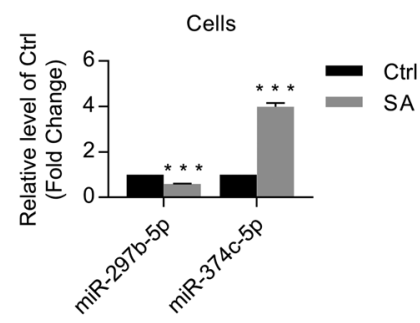

C

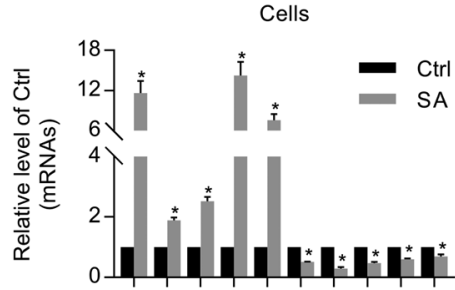

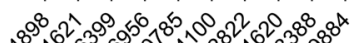

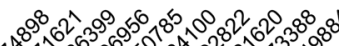

B

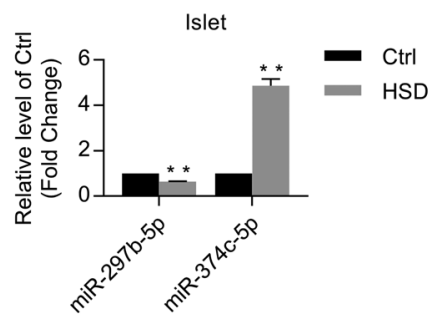

D
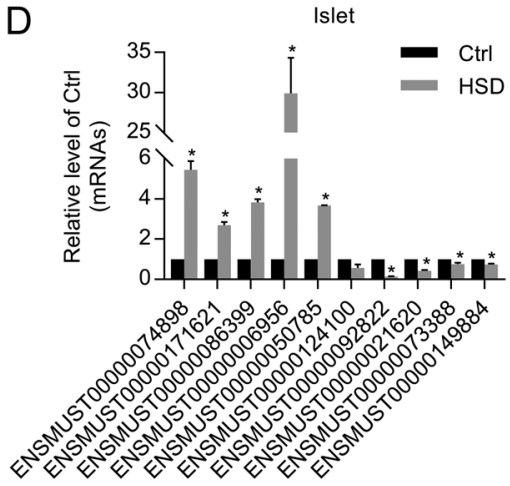

\section{Figure 7}

Validation of differentially expressed miRNAs and mRNAs in $\beta$-TC- 6 cells and mouse islets by qRT-PCR. (A and B) Verification of candidate miRNA (miR-297b-5p and miR-374c-5p) expression in stearic-acid-treated $\beta$-TC- 6 cells and high-stearic-acid-fed mouse islets. (C and D) Quantitative real-time PCR confirmation of the top five significantly up- or down-regulated mRNAs in $\beta-$ TC-6 cells treated with stearic acid and in islets from high-stearic-acid diet fed mice. ( $E$ and F) Validation of miR-297b-5p and miR-374c-5p expression in stearic-acid-treated AML-12 cells and different mouse tissues fed a high-stearic-acid diet by quantitative real-time PCR. Ctrl, control group; SA, stearic acid; HSD, high-stearic-acid diet. All data are presented as the mean \pm S.E.M. of three independent cell cultures or five mice per group. ${ }^{*} P<0.05$, $\star * P<0.01$ and $* * \star P<0.001$ vs the Ctrl group. levels were apparently increased (Fig. 9B), whereas no remarkable changes were observed in the five most up-regulated expressions of ENSMUST00000074898, ENSMUST00000171621, ENSMUST00000086399, ENSMUST00000006956 and ENSMUST0000005078 (Fig. 9A). Meanwhile, the levels of ENSMUST00000074898 and ENSMUST00000006956 were increased, whereas the ENSMUST00000124100, ENSMUST00000092822 and ENSMUST00000021620 expressions were apparently reduced after incubation of AMO-297b-5p alone in the absence of stearic acid (Fig. 9A and B).

After inhibition of miR-374c-5p in stearicacid-treated $\beta$-TC- 6 cells, the down-regulated mRNA expressions of ENSMUST00000124100, ENSMUST00000021620, ENSMUST00000073388 and ENSMUST00000149884 as well as up-regulated ENSMUST00000171621 and ENSMUST00000006956 were significantly reversed, especially for ENSMUST00000124100, ENSMUST00000149884 and ENSMUST00000006956 (Fig. 10A and B). When silencing miR-374c-5p in absence of stearic acid, the five most down-regulated mRNAs

ENSMUST00000092822, ENSMUST00000073388 and ENSMUST00000149884 expressions were obviously increased, among which the levels of ENSMUST00000124100 and ENSMUST00000149884 were the top two highest (Fig. 10B). However, there is no significant change in the levels of the five most up-regulated mRNAs (Fig. 10A). Additionally, overexpression of miR-374c-5p only decreased the ENSMUST00000021620 mRNA level and increased ENSMUST00000074898 and ENSMUST00000006956 expressions after transfection of miR-374c-5p mimic alone, respectively (Fig. 10A and B).

\section{Discussion}

Chronic exposure to elevated SFAs is a leading cause of $\beta$-cell dysfunction in the pathogenesis and development of T2DM, which to date has no effective preventive treatment. Recently, miRNAs have become attractive 
A

A

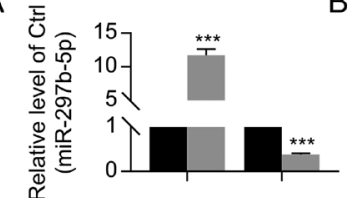

mimic-NC + -

297 mimic - +

AMO-NC AMO-297

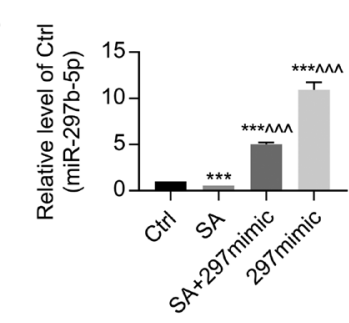

$\mathrm{C} \stackrel{2}{\circ}$

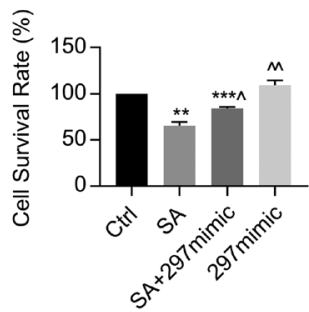

D

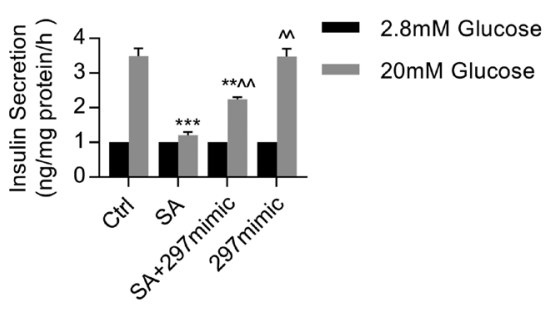

F
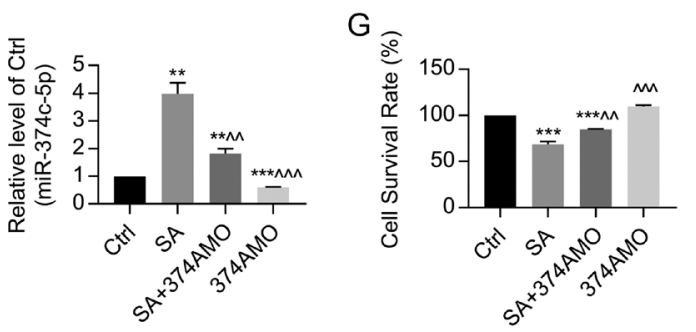

E
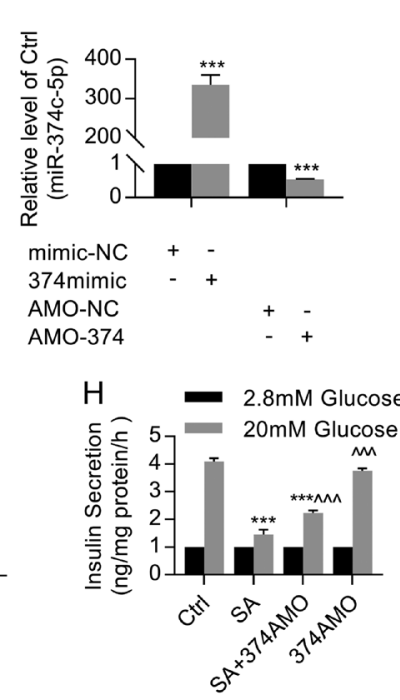

\section{Figure 8}

The role of miR-297b-5p and miR-374c-5p in stearic-acid-induced reduction of cell viability and GSIS in $\beta$-TC- 6 cells. (A) The transfection efficiency of miR-297b-5p mimic and AMO in the absence of stearic acid. (B) Verification of miR-297b-5p level in the presence of stearic acid by qRT-PCR. (C) Measurement of cell viability after transfection of AMO-297b-5p in stearic acid-treated $\beta$-TC- 6 cells. (D) Effect of AMO-297b-5p on GSIS after stearic acid treatment. (E) The inhibitory rate of AMO-374c-5p and over-expression rate of miR-374c-5p mimic without stearic acid treatment. (F) Alteration of intracellular miR374c-5p expression after miR-374c-5p mimic transfection in stearic-acid-treated $\beta$-TC- 6 cells. (G) Effect AMO-374c-5p on stearic-acid-decreased cell survival rate. $(\mathrm{H})$ Restoration of stearic-acidimpaired GSIS after transfection of AMO-374c-5p. Ctrl, control group; NC, negative control; SA, stearic acid; 297/374mimic, miR-297b/374c-5p mimic; 297/374AMO, anti-miRNA-297b/374c-5p oligonucleotide. $* P<0.05, * * P<0.01$ and $\star \star \star * P<0.001$ vs the Ctrl group; ${ }^{\wedge} P<0.05,{ }^{\wedge} P<0.01$ and ${ }^{\wedge \wedge} p<0.001$ vs the SA group. $n=3$ independent cell cultures per group, and all data are presented as the mean \pm S.E.M. candidates for manipulation because of their regulatory role in mRNA transcription and protein translation. We used HiSeq sequencing technology to profile miRNAs and mRNAs and to reveal regulatory networks in SFA-impaired $\beta$-TC- 6 cells, and we compared the effects of stearic acid and palmitic acid for the first time. Although the majority of studies examining elevated levels of SFA-induced worsening of $\beta$-cell function in the development of T2DM have focused on palmitic acid (Marafie et al. 2019, Nemecz et al. 2019), accumulated evidence indicates that increased levels of stearic acid have a critical role in $\beta$-cell dysfunction (Lu et al. 2016a, Šrámek et al. 2017). In this study, we demonstrated that stearic acid has a stronger effect on $\beta$-TC- 6 cells than palmitic acid, similar to results in other $\beta$-cell lines (Fürstova et al. 2008). Nevertheless, the impact of stearic acid on $\beta$-cells and the mechanisms by which it acts are poorly understood.

Pancreatic $\beta$-cell dysfunction in response to SFAs is associated with changes in the expression of proteincoding and non-coding transcripts. Recent studies show that miRNAs can serve as important regulators of $\beta$-cell functions (Plaisance et al. 2014, Guay \& Regazzi 2015, Özcan 2015). In a previous study (Lu et al. 2016a), we employed gene chip technology to examine changes in miRNA levels in islets from high-stearic-acid-fed mice. However, the miRNA profile in the present study is different from that of our previous study. First, compared

(c) 2020 Society for Endocrinology Published by Bioscientifica Ltd. Printed in Great Britain with gene chip technology, high throughput sequencing is able to identify many novel unannotated genes and more effectively detects genes with lower expression. Second, the mRNA profile was determined in the present study but not in the previous project. In this study, we used $\beta$-TC- 6 cells, a mouse insulinoma cell line, as a model to determine the miRNA and mRNA network after stearic acid or palmitic acid treatment. We then selected the differentially expressed miRNAs and mRNAs, especially in the stearic-acid-treated group. We validated the levels of miR-374c-5p and miR-297b-5p in various tissues from high-stearic-acid-fed mice and in cell lines treated with stearic acid. Similar changes in expression were consistently observed for these two miRNAs in primary mouse islets and $\beta$-TC- 6 cells. Meanwhile, the two miRNAs were identified to be involved in stearic-acid-impaired cell viability and insulin secretion in $\beta$-TC- 6 cells, of which the effect of miR-297b-5p on stearic-acid-induced reduction of cell viability and GSIS is consistent with our previous study (Guo et al. 2020). These findings indicate that miR-297b-5p and miR-374c-5p can potentially act as important predictors in stearic-acid-induced $\beta$-cell failure.

The second important finding of this study was to identify miRNAs and target mRNAs in $\beta$-cells that are specifically dysregulated by stearic acid and not palmitic acid. To gain insight into the potential roles of differentially expressed miRNAs in stearic-acid-induced dysfunctional 
A

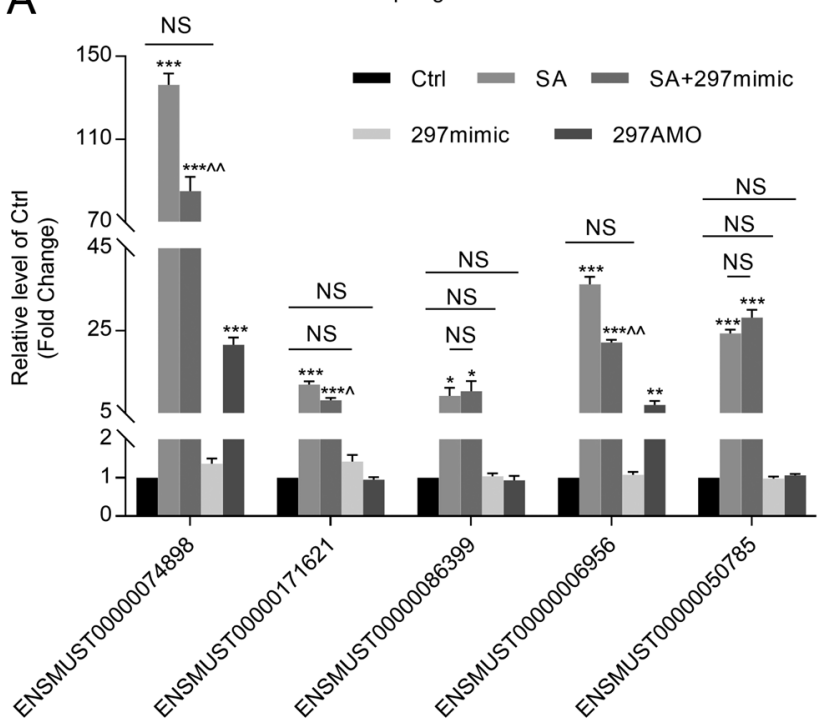

B

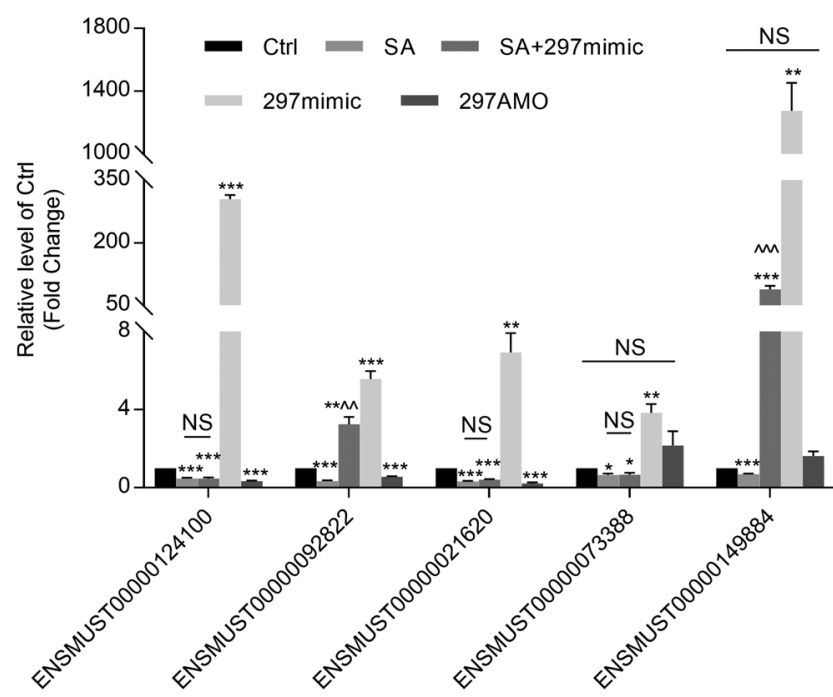

Figure 9

Alterations of candidate mRNAs expressions after transfection of miR-297b-5p mimic. (A) Effect of miR-297b-5p mimic on stearic-acidinduced five most up-regulated mRNAs levels. (B) Effect of miR-297b-5p mimic on stearic-acid-induced five most down-regulated mRNAs expressions. Ctrl, control group; SA, stearic acid; 297mimic, miR-297b-5p mimic; 297AMO, anti-miRNA-297b-5p oligonucleotide. All data are shown as the mean \pm S.E.M. of three independent cell experiments. ${ }^{*} P<0.05$, $\star * P<0.01$ and $* * * P<0.001$ vs the Ctrl group; ${ }^{\wedge} P<0.05,{ }^{\wedge} P<0.01$ and ${ }^{\wedge \wedge} P<0.001$ vs the SA group; NS, no statistical significance.

$\beta$-cells, we performed GO and pathway analysis. We found that the dysregulated miRNAs and mRNAs were most highly enriched in binding, cell part, long-term potentiation, insulin secretion, vascular smooth muscle contraction and T2DM. Besides, we selected the top five up- and down-regulated mRNAs that are differentially expressed
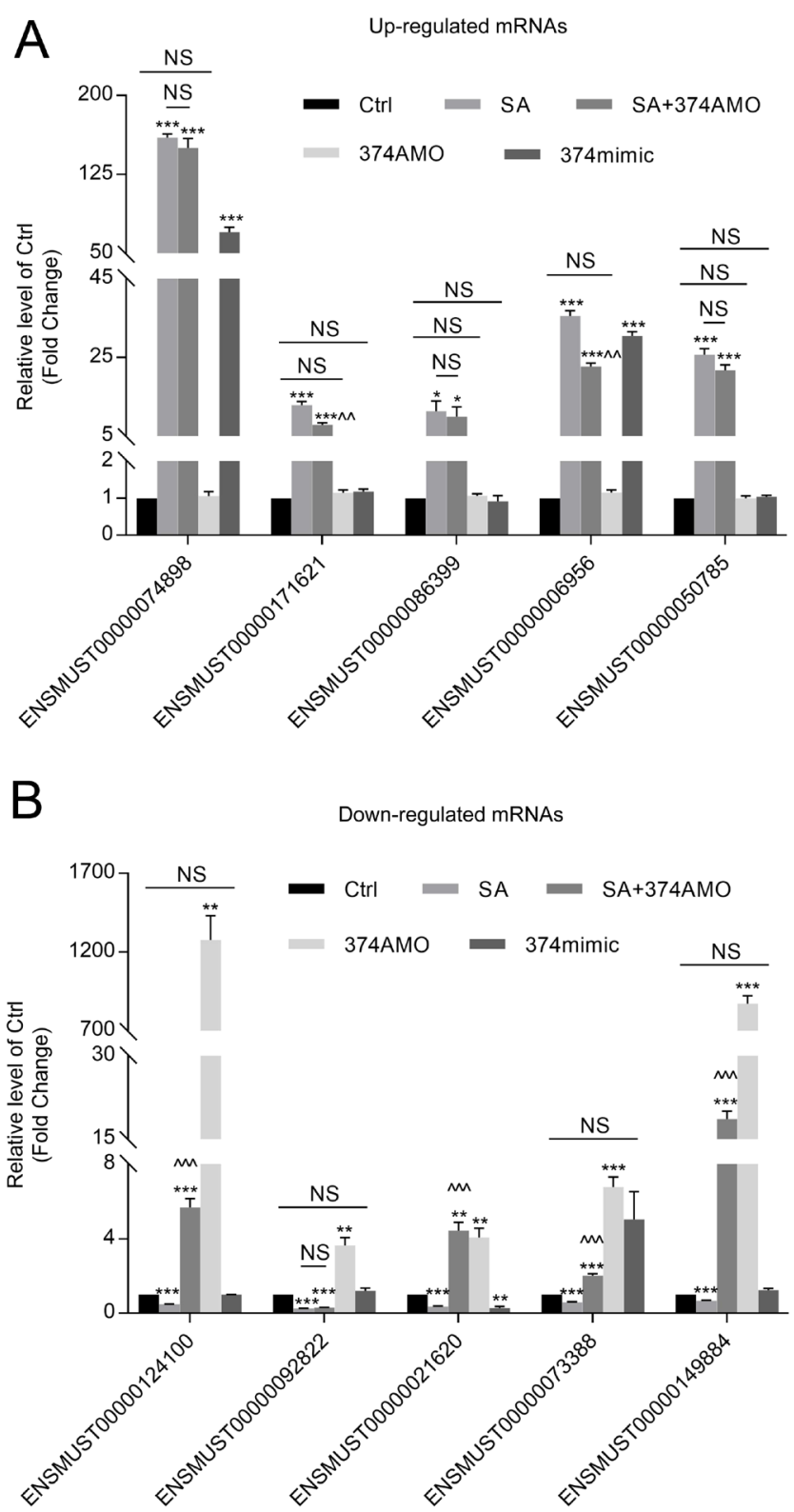

Figure 10

Alterations of candidate mRNAs expressions after transfection of AMO-374c-5p. (A) Changes in the expressions of five most up-regulated mRNAs after transfection of AMO-374c-5p in the presence of stearic acid. (B) The levels of top five stearic-acid-decreased mRNAs transfected with AMO-374c-5p. Ctrl, control group; SA, stearic acid; 374mimic, miR-374c-5p mimic; 374AMO, anti-miRNA-374c-5p oligonucleotide. $* P<0.05, * * P<0.01$ and $* * * P<0.001$ vs the Ctrl group; ${ }^{\wedge} P<0.01$ and ${ }^{\wedge \wedge} P<0.001$ vs the SA group; NS, no statistical significance. Values are expressed as mean \pm S.E.M. $(n=3)$.

specific to stearic acid and investigated the change in the expression of these candidate mRNAs after transfection of mimic/AMO of miR-297b-5p or miR-374c-5p into $\beta$-TC- 6 cells in the presence or absence of stearic acid and then preliminarily screened the mRNAs potentially targeted by miR-297b-5p or miR-374c-5p which were involved 
in the process of stearic-acid-induced $\beta$-cell dysfunction. Our results demonstrated that overexpression of miR297b-5p could significantly reverse stearic-acid-increased ENSMUST00000074898 (Hp), ENSMUST00000171621 (Tifa) and ENSMUST00000006956 (Saa3) level, which indicated that miR-297b-5p may play an important role by targeting Hp, Tifa or Saa3 in stearic-acid-stimulated lipotoxicity to $\beta$ cells. For miR-374c-5p, we focused on ENSMUST00000124100 (Prn), ENSMUST00000021620 (Otub2) and ENSMUST00000149884 (Snapin), the expression of which was apparently inversed after inhibition of miR-374-5p with stearic acid treatment. It appears that Prn, Otub2 and Snapin are possibly targets for miR-374c-5p in stearic-acid-induced $\beta$ cell dysfunction.

Although long-term high-stearic-acid-diet-induced $\beta$-cell dysfunction has been broadly characterized as a trigger of type 2 diabetes (Lu et al. 2016a, Roomp et al. 2017), the stearic and palmitic acids, whether in the diet or serum, are actually mixed. Therefore, we further performed another critical analysis of the differentially expressed miRNAs and mRNAs profiles and their co-expression network specific to palmitic acid as well as in common to both of these two fatty acids in $\beta$-cell function. In palmitic-acid-treated cells, NovelmiRNA-639 was observed increased by $5.107 \log 2$ (fold-change) but not detected in $\beta$-TC- 6 cells exposed to stearic acid, compared with normal group. Meanwhile, miR-21a-5p and miR$34 a-5 p$ were differentially expressed both in stearic acid and palmitic acid group. These results could become a deeper knowledge of miRNA-mRNA regulatory pathway alterations in the development of SFAs induced $\beta$-cell dysfunction. This is another key finding of this study.

Alternatively, unsaturated fatty acids have been described to show protective effects in pancreatic $\beta$-cells (Morgan \& Dhayal 2010, Acosta-Montaño \& GarcíaGonzález 2018, Dhayal et al. 2019). In the current study, we observed that a number of unsaturated fatty acids such as linoleic acid (C18:3, LNA), palmitoleic acid (C16:1, PLA), eicosapentaenoic acid and (C20:5, EPA) were decreased in HSD mice, which would contribute to the alterations of miRNA/mRNA profiles in vivo.

We are well aware that the present study contains a number of limitations. First, the number of samples analyzed was relatively small. Second, we focused on the five most up- or down-regulated differentially expressed mRNAs; therefore, other mRNAs need further identification. In addition, although we found that miR-297b-5p is involved in stearic-acid-induced $\beta$-TC-6 cell apoptosis by targeting LATS2 in our previous study (Guo et al. 2020), the precise mechanisms and many other direct targets by which miR-297b-5p as well as miR-374c-5p participate in stearic-acid-induced $\beta$-cell dysfunction require further exploration in in vitro and in vivo experiments.

In conclusion, we determined miRNA and mRNA expression patterns and their co-network in $\beta$-cells. Combined with bioinformatic analysis, we identified miR-374c-5p and miR-297b-5p as important nodes in the regulation of stearic-acid-induced lipotoxicity of pancreatic $\beta$-cells, especially compared with palmitic-acidtreated cells. These findings indicate an important role of miRNAs and related targets and pathways as predictors of responses to high-stearic-acid-diet-induced $\beta$-cell dysfunction in the progression of T2DM.

\section{Supplementary materials}

This is linked to the online version of the paper at https://doi.org/10.1530/ JOE-20-0055.

\section{Declaration of interest}

The authors declare that there is no conflict of interest that could be perceived as prejudicing the impartiality of the research reported.

\section{Funding}

This work was supported by the University Nursing Program for Young Scholars with Creative Talents in Heilongjiang Province (UNPYSCT-201705); National Natural Science Foundation of China (No. 81773424); Fundamental Research Funds for the Provincial Universities of Heilongjiang (2017JCZX16) and the Postdoctoral Scientific Research Developmental Fund of Heilongjiang province (grant number LBH-Q16169).

\section{Acknowledgements}

$\mathrm{H} L$ and $C \mathrm{~S}$ conceived and designed the experiments. $Y \mathrm{Y}, \mathrm{R} G$ and $Y Z$ performed the experiments. $Y Y$ and $H \mathrm{~L}$ analyzed data and wrote the manuscript. $\mathrm{H}$ Shi, $\mathrm{H}$ Sun and $\mathrm{X} W$ calculated the Pearson correlation coefficients. $H \mathrm{~L}, Y Y$ and $X C$ reviewed and edited the manuscript. The authors thank Jeremy Allen, PhD, from Liwen Bianji, Edanz Group China (www. liwenbianji.cn/ac), for editing the English text of a draft of this manuscript.

\section{References}

Acosta-Montaño P \& García-González V 2018 Effects of dietary fatty acids in pancreatic beta cell metabolism, implications in homeostasis. Nutrients 10 393. (https://doi.org/10.3390/nu10040393) Acosta-Montaño P, Rodríguez-Velázquez E, Ibarra-López E, Frayde-Gómez H, Mas-Oliva J, Delgado-Coello B, Rivero IA, Alatorre-Meda M, Aguilera J, Guevara-Olaya L, et al. 2019 Fatty acid and lipopolysaccharide effect on beta cells proteostasis and its impact on insulin secretion. Cells $\mathbf{8} 884$. (https://doi.org/10.3390/ cells8080884) 
Ambros V 2004 The functions of animal microRNAs. Nature 431 350-355. (https://doi.org/10.1038/nature02871)

Bartel DP 2018 Metazoan microRNAs. Cell 173 20-51. (https://doi. org/10.1016/j.cell.2018.03.006)

Belgardt BF, Ahmed K, Spranger M, Latreille M, Denzler R, Kondratiuk N, von Meyenn F, Villena FN, Herrmanns K, Bosco D, et al. 2015 The microRNA-200 family regulates pancreatic beta cell survival in type 2 diabetes. Nature Medicine 21 619-627. (https://doi.org/10.1038/ $\mathrm{nm} .3862)$

Chen C, Cohrs CM, Stertmann J, Bozsak R \& Speier S 2017 Human beta cell mass and function in diabetes: recent advances in knowledge and technologies to understand disease pathogenesis. Molecular Metabolism 6 943-957. (https://doi.org/10.1016/j. molmet.2017.06.019)

Chu X, Liu L, Na L, Lu H, Li S, Li Y \& Sun C 2013 Sterol regulatory element-binding protein-1c mediates increase of postprandial stearic acid, a potential target for improving insulin resistance, in hyperlipidemia. Diabetes 62 561-571. (https://doi.org/10.2337/db120139)

Dhayal S, Zummo FP, Anderson MW, Thomas P, Welters HJ, Arden C \& Morgan NG 2019 Differential effects of saturated and unsaturated fatty acids on autophagy in pancreatic $\beta$-cells. Journal of Molecular Endocrinology 63 285-296. (https://doi.org/10.1530/JME-19-0096)

Elsner M, Gehrmann W \& Lenzen S 2011 Peroxisome-generated hydrogen peroxide as important mediator of lipotoxicity in insulinproducing cells. Diabetes 60 200-208. (https://doi.org/10.2337/db091401)

Flynt AS \& Lai EC 2008 Biological principles of microRNA-mediated regulation: shared themes amid diversity. Nature Reviews: Genetics 9 831-842. (https://doi.org/10.1038/nrg2455)

Fürstova V, Kopska T, James RFL \& Kovar J 2008 Comparison of the effect of individual saturated and unsaturated fatty acids on cell growth and death induction in the human pancreatic $\beta$-cell line NES2Y. Life Sciences 82 684-691. (https://doi.org/10.1016/j.lfs.2007.12.023)

GBD 2015 Disease and Injury Incidence and Prevalence Collaborators 2016 Global, regional, and national incidence, prevalence, and years lived with disability for 310 diseases and injuries, 19902015: a systematic analysis for the Global Burden of Disease Study 2015. Lancet 388 1545-1602. (https://doi.org/10.1016/S01406736(16)31678-6)

Gehrmann W, Elsner M \& Lenzen S 2010 Role of metabolically generated reactive oxygen species for lipotoxicity in pancreatic $\beta$-cells. Diabetes, Obesity and Metabolism 12 149-158. (https://doi.org/10.1111/j.14631326.2010.01265.x)

Giacca A, Xiao C, Oprescu AI, Carpentier AC \& Lewis GF 2011 Lipidinduced pancreatic $\beta$-cell dysfunction: focus on in vivo studies. American Journal of Physiology: Endocrinology and Metabolism 300 E255-E262. (https://doi.org/10.1152/ajpendo.00416.2010)

Goldstein JL, Basu SK \& Brown MS 1983 Receptor-mediated endocytosis of low-density lipoprotein in cultured cells. In Methods in Enzymology, pp. 241-260. Cambridge, MA, USA: Academic Press. (https://doi. org/10.1016/0076-6879(83)98152-1)

Guay C \& Regazzi R 2015 MicroRNAs and the functional $\beta$ cell mass: for better or worse. Diabetes and Metabolism 41 369-377. (https://doi. org/10.1016/j.diabet.2015.03.006)

Guo R, Yu Y, Zhang Y, Li Y, Chu X, Lu H \& Sun C 2020 Overexpression of miR-297b-5p protects against stearic acid-induced pancreatic $\beta$-cell apoptosis by targeting LATS2. American Journal of Physiology: Endocrinology and Metabolism 318 E430-E439. (https://doi org/10.1152/ajpendo.00302.2019)

Jiang Q, Wang Y, Hao Y, Juan L, Teng M, Zhang X, Li M, Wang G \& Liu Y 2009 miR2Disease: a manually curated database for microRNA deregulation in human disease. Nucleic Acids Research 37 D98-D104. (https://doi.org/10.1093/nar/gkn714)

Li XG, Li L, Zhou X, Chen Y, Ren YP, Zhou TY \& Lu W 2012 Pharmacokinetic/pharmacodynamic studies on exenatide in diabetic rats. Acta Pharmacologica Sinica 33 1379-1386. (https://doi. org/10.1038/aps.2012.33)

Listenberger LL, Han X, Lewis SE, Cases S, Farese Jr RV, Ory DS \& Schaffer JE 2003 Triglyceride accumulation protects against fatty acidinduced lipotoxicity. PNAS 100 3077-3082. (https://doi.org/10.1073/ pnas.0630588100)

Lu H, Hao L, Li S, Lin S, Lv L, Chen Y, Cui H, Zi T, Chu X, Na L, et al. $2016 a$ Elevated circulating stearic acid leads to a major lipotoxic effect on mouse pancreatic beta cells in hyperlipidaemia via a miR-34a-5pmediated PERK/p53-dependent pathway. Diabetologia 59 1247-1257. (https://doi.org/10.1007/s00125-016-3900-0)

Lu Y, Wang Y, Ong CN, Subramaniam T, Choi HW, Yuan JM, Koh WP $\&$ Pan A 2016b Metabolic signatures and risk of type 2 diabetes in a Chinese population: an untargeted metabolomics study using both LC-MS and GC-MS. Diabetologia 59 2349-2359. (https://doi. org/10.1007/s00125-016-4069-2)

Lu Y, Wang Y, Zou L, Liang X, Ong CN, Tavintharan S, Yuan JM, Koh WP \& Pan A 2018 Serum lipids in association with Type 2 diabetes risk and prevalence in a Chinese population. Journal of Clinical Endocrinology and Metabolism 103 671-680. (https://doi.org/10.1210/ jc.2017-02176)

Marafie SK, Al-Shawaf EM, Abubaker J \& Arefanian H 2019 Palmitic acidinduced lipotoxicity promotes a novel interplay between Akt-mTOR, IRS-1, and FFAR1 signaling in pancreatic $\beta$-cells. Biological Research 52 44. (https://doi.org/10.1186/s40659-019-0253-4)

Morgan NG \& Dhayal S 2010 Unsaturated fatty acids as cytoprotective agents in the pancreatic beta-cell. Prostaglandins, Leukotrienes, and Essential Fatty Acids 82 231-236. (https://doi.org/10.1016/j. plefa.2010.02.018)

Nemecz M, Constantin A, Dumitrescu M, Alexandru N, Filippi A, Tanko G \& Georgescu A 2019 The distinct effects of palmitic and oleic acid on pancreatic beta cell function: the elucidation of associated mechanisms and effector molecules. Frontiers in Pharmacology 91554. (https://doi.org/10.3389/fphar.2018.01554)

Özcan S 2015 MicroRNAs in pancreatic $\beta$-cell physiology. In MicroRNA: Basic Science: From Molecular Biology to Clinical Practice, pp. 101-117. Ed G Santulli. Cham, Switzerland: Springer International Publishing. (https://doi.org/10.1007/978-3-319-22380-3_6)

Plaisance V, Waeber G, Regazzi R \& Abderrahmani A 2014 Role of microRNAs in islet beta-cell compensation and failure during diabetes. Journal of Diabetes Research 2014 618652. (https://doi. org/10.1155/2014/618652)

Pordzik J, Jakubik D, Jarosz-Popek J, Wicik Z, Eyileten C, De Rosa S, Indolfi C, Siller-Matula JM, Czajka P \& Postula M 2019 Significance of circulating microRNAs in diabetes mellitus type 2 and platelet reactivity: bioinformatic analysis and review. Cardiovascular Diabetology 18 113. (https://doi.org/10.1186/s12933-019-0918-x)

Risérus U, Willett WC \& Hu FB 2009 Dietary fats and prevention of type 2 diabetes. Progress in Lipid Research 48 44-51. (https://doi. org/10.1016/j.plipres.2008.10.002)

Roomp K, Kristinsson H, Schvartz D, Ubhayasekera K, Sargsyan E, Manukyan L, Chowdhury A, Manell H, Satagopam V, Groebe K, et al. 2017 Combined lipidomic and proteomic analysis of isolated human islets exposed to palmitate reveals time-dependent changes in insulin secretion and lipid metabolism. PLOS ONE 12 e0176391. (https://doi org/10.1371/journal.pone.0176391)

Smyth S \& Heron A 2006 Diabetes and obesity: the twin epidemics. Nature Medicine 12 75-80. (https://doi.org/10.1038/nm0106-75)

Song Y, Jin D, Jiang X, Lv C \& Zhu H 2018 Overexpression of microRNA-26a protects against deficient $\beta$-cell function via targeting phosphatase with tensin homology in mouse models of type 2 diabetes. Biochemical and Biophysical Research Communications 495 1312-1316. (https://doi.org/10.1016/j.bbrc.2017.11.170)

Šrámek J, Němcová-Fürstová V, Pavlíková N \& Kovář J 2017 Effect of saturated stearic acid on MAP kinase and ER stress signaling pathways during apoptosis induction in human pancreatic $\beta$-cells is inhibited https://joe.bioscientifica.com

https://doi.org/10.1530/JOE-20-0055 (c) 2020 Society for Endocrinology Published by Bioscientifica Ltd. Printed in Great Britain 
by unsaturated oleic acid. International Journal of Molecular Sciences 18 2313. (https://doi.org/10.3390/ijms18112313)

Sutton R, Peters M, McShane P, Gray DWR \& Morris PJ 1986 Isolation of rat pancreatic islets by ductal injection of collagenase. Transplantation 42 689-690. (https://doi.org/10.1097/00007890198612000-00022)

Tholstrup T, Hjerpsted J \& Raff M 2011 Palm olein increases plasma cholesterol moderately compared with olive oil in healthy individuals. American Journal of Clinical Nutrition 94 1426-1432. (https://doi.org/10.3945/ajcn.111.018846)

van den Berg SA, Guigas B, Bijland S, Ouwens M, Voshol PJ, Frants RR, Havekes LM, Romijn JA \& van Dijk KW 2010 High levels of dietary stearate promote adiposity and deteriorate hepatic insulin sensitivity. Nutrition and Metabolism 7 24. (https://doi.org/10.1186/17437075-7-24)

Welsh N, Cnop M, Kharroubi I, Bugliani M, Lupi R, Marchetti P \& Eizirik DL 2005 Is there a role for locally produced interleukin-1 in the deleterious effects of high glucose or the type 2 diabetes milieu to human pancreatic islets? Diabetes 54 (Supplement 97) 3238-3244. (https://doi.org/10.2337/diabetes.54.11.3238)

Zhu H \& Leung SW 2015 Identification of microRNA biomarkers in type 2 diabetes: a meta-analysis of controlled profiling studies. Diabetologia 58 900-911. (https://doi.org/10.1007/s00125015-3510-2)

Received in final form 16 March 2020

Accepted 17 April 2020

Accepted Manuscript published online 17 April 2020 (c) 2020 Society for Endocrinology Published by Bioscientifica Ltd.
Printed in Great Britain 